\title{
Top-Down Knowledge Hiding in Organizations: An Empirical Study of the Consequences of Supervisor Knowledge Hiding Among Local and Foreign Workers in the Middle East
}

\section{Ghulam Ali Arain, Ph.D}

Associate Professor

Department of Management, School of Business

American University of Ras Al Khaimah, United Arab Emirates

drghulamaliarain@gmail.com (Personal)

Ghulam.arain@aurak.ac.ae (Official/Institutional)

\section{Zeeshan Ahmed Bhatti, Ph.D (Corresponding Author)}

Assistant Professor, Department of MIS, Faculty of Economics and Administration

King AbdulAziz University, Jeddah, Saudi Arabia

xeeshan@gmail.com (Personal)

zbhatti@kau.edu.sa (Official/Institutional)

Phone (Cell): +966-551290123

Phone (Off): +966-12-6952000 Ext: 60826

\section{Naeem Ashraf, Ph.D}

Assistant Professor, Department of Entrepreneurship and Strategy

Montpellier Business School, Montpellier, France

naeem.ashrf@gmail.com

\section{Yu-Hui Fang, Ph.D}

Associate Professor, Department of Accounting

Tamkang University, New Taipei City, Taiwan

yhfang@mail.tku.edu.tw 


\begin{abstract}
This study adds to the growing research exploring the consequences of knowledge hiding in organizations. Drawing from the social exchange theory and the norm of reciprocity, this paper examines the direct and indirect - via distrust in supervisor - relationships between supervisor knowledge hiding (SKH) and supervisee organizational citizenship behavior directed at the supervisor (OCB-S) in the context of the Middle East.

Using a supervisor-supervisee dyadic design, two-source data were obtained from 317 employees (local and foreign) of 41 Saudi firms. The findings suggest that supervisees' distrust in their supervisors mediates the significant and negative relationship between SKH and supervisees' OCB-S. Furthermore, the significant and positive relationship between SKH and distrust in supervisor is more pronounced for foreign workers than for local workers. This study provides empirical support and a better understanding of the existence and consequences of SKH for local foreign workers and also discusses the theoretical and practical implications of the findings.
\end{abstract}

Keywords: Knowledge hiding; distrust in supervisor; organizational citizenship behavior directed at the supervisor; the Kingdom of Saudi Arabia. 


\section{INTRODUCTION}

The success of an organization in achieving and maintaining its competitiveness is often attributed to the effectiveness of its knowledge management system which mostly relies on its employees' motivation to exhibit knowledge sharing behavior (Bavik, Tang, Shao, \& Lam, 2017; Gagné, 2009; Riege, 2005). While ample research has highlighted the potential benefits of knowledge sharing for organizational growth and financial performance (Andreeva \& Kianto, 2012; Mesmer-Magnus \& DeChurch, 2009), annual losses amounting to $\$ 31.5$ billion in Fortune 500 companies have been attributed to knowledge hiding (Babcock, 2004), which is defined as "an intentional attempt by an individual to withhold or conceal knowledge that has been requested by another person" (Connelly et al. 2012; p. 65). Knowledge hiding, particularly in its evasive-hiding form and playing-dumb form, which are based on deception - is antisocial and unethical employee behavior that threatens the employee's moral norms - sharing knowledge with coworkers and helping the organization maintain its competitiveness (Bavik et al., 2017; Lin, 2007). Although knowledge hiding has been shown to impose a significant financial burden upon organizations (Babcock, 2004), far less is known about the cost it inflicts upon employee prosocial and ethical behaviors (Connelly \& Zweig, 2015; Connelly, Zweig, Webster, \& Trougakos, 2012). Thus, we aim to examine the consequences of supervisor knowledge hiding (SKH) for supervisees' prosocial behavior, i.e., organizational citizenship behavior directed at the supervisor (OCB-S) (Masterson, Lewis, Goldman, \& Taylor, 2000). In doing so, we seek to extend the scarce literature on knowledge hiding in a number of important ways as explained below.

First, while only a handful of empirical studies (i.e., Černe, Hernaus, Dysvik, \& Škerlavaj, 2017; Černe, Nerstad, Dysvik, \& Škerlavaj, 2014; Connelly \& Zweig, 2015; Peng, Wang, \& Chen, 2018; Serenko \& Bontis, 2016; Škerlavaj, Connelly, Cerne, \& Dysvik, 2018) examine the 
consequences of knowledge hiding at the horizontal level, i.e., between two coworkers, the consequences of this unethical behavior at the vertical level, i.e., between a supervisor and a supervisee, are yet to be explored (Connelly \& Zweig, 2015). Given the prior research suggests that unethical leadership or supervisory behaviors, i.e., abusive supervision (Mackey, Frieder, Brees, \& Martinko, 2017) and self-serving leadership (Peng et al., 2018), have severe implications for the follower or supervisee work attitudes and behaviors, it is probable that the consequences of $\mathrm{SKH}$ is more devastating for the workplace outcomes than the consequences of coworker knowledge hiding. Thus, by focusing on SKH, this study contributes to both knowledge hiding and unethical leadership/supervisory behavior literatures.

Second, the handful of recent studies that examined the behavioral consequences of coworker knowledge hiding mostly focused on 'reciprocal knowledge hiding' as one of the most likely reactions of the victim of knowledge hiding against the culprit of knowledge hiding (Černe et al., 2017; Černe et al., 2014; Connelly \& Zweig, 2015; Serenko \& Bontis, 2016). Drawing from the social exchange theory (Blau, 1964) and the norm of reciprocity (Gouldner, 1960), it is suggested that negative reciprocity "involves the tendency to return negative treatment for negative treatment" (Cropanzano and Mitchell 2005; p. 878), and motivates the victim of knowledge hiding to respond to the perpetrator by engaging in reciprocal knowledge hiding from the perpetrator. However, considering the control that supervisors have on pay and perks for supervisees, it is more likely that supervisees balance their negative social exchange with the supervisor through reducing extra-role behaviors, i.e., OCB-S, rather than reciprocal knowledge hiding, which may cause them further resources depletion. Thus, extending the literature, we examine the effect of SKH on supervisees' OCB-S which, though extra-role, is crucial for supervisors' managerial effectiveness 
(Masterson et al., 2000; Meyer, Ohana, \& Stinglhamber, 2017; Podsakoff, Whiting, Podsakoff, \& Blume, 2009).

Third, understanding of the relationship between SKH and supervisees' OCB-S would not be complete without explaining whether this is a direct or an indirect relationship; and in case of an indirect relationship, what is the underlying mechanism? To fully explain this relationship, we invoke the social exchange theory (Blau, 1964) and the norm of reciprocity (Gouldner, 1960) to explore the role of 'distrust' as the underlying motivational mechanism through which the effect of SKH is transferred to supervisees' OCB-S. Specifically, we suggest that SKH first results in supervisees' distrust in their supervisor - confident expectations regarding the supervisor's harmful conduct (Lewicki, McAllister, \& Bies, 1998) - which, in turn, motivates the supervisees to reduce their OCB-S to balance the negative exchange with the supervisor. By exploring this mediation-based indirect relationship, we contribute to the knowledge-hiding literature, which has mostly examined the direct relationships between knowledge hiding and negative work attitudes and behaviors.

Fourth, we conducted this study in the relatively unexplored work setting of the Kingdom of Saudi Arabia (KSA)- the world's largest oil producer and the wealthiest of the Middle Eastern countries (Nurunnabi, 2017). Due to its economic dependence on oil export, the KSA has attracted a massive number of foreign workers ${ }^{1}-$ who make up approximately one-third of its total workforce. This, in turn, has made employee work relationships in Saudi organizations very complicated and somewhat discriminatory. For instance, prior research on employee relationships

\footnotetext{
${ }^{1}$ We define 'foreign' workers as those employees who do not have permanent residential status in the KSA (i.e., the host country) and whose work visas are sponsored by Saudi firms. Thus, they are different from 'expatriate' workers whose overseas assignments are sponsored by their home country firms (Ang, Van Dyne, \& Begley, 2003; Guzzo, Noonan, \& Elron, 1994).
} 
in the Saudi work context (Mellahi, 2007; Yeo \& Marquardt, 2015) suggests that Saudi employees are considerably more privileged than their foreign counterparts who have significantly fewer incentives (both monetary and nonmonetary), lesser job autonomy and job security, lower bargaining power, and fewer rights to raise their voice against any supervisory abuse, particularly when their supervisor is Saudi (Mellahi, 2007). Considering this, we conducted a multigroup analysis (MGA) of Saudis versus foreign workers to examine whether our hypothesized model differs significantly for the two groups.

In summary, our study answers three questions: What is the relationship between SKH and supervisee OCB-S? (2) How does this relationship work? And (3) for which employees (i.e., local versus foreign) does this relationship matter more?

The paper proceeds as follows. The following section addresses the theoretical foundation of the research and develops the hypotheses. The subsequent sections are related to the methodology, analyses, and results. The paper concludes with discussions related to the research findings, the theoretical and practical implications, the research limitations, and future research directions.

\section{THEORY AND HYPOTHESIS DEVELOPMENT}

\section{The context of the Kingdom of Saudi Arabia (KSA)}

The KSA, which is a member of the G20 and the largest exporter of oil and gas products, is a leading country of the Gulf Cooperation Council (GCC). The country experienced an exponential economic and financial growth during the oil boom in the 1970 s, which led to the creation of thousands of jobs in Saudi Arabia. There was a massive demand for skilled workforce in the KSA which could not be met by the Saudi workforce. Organizations in the KSA hired skilled foreign workers to meet this growing demand. This resulted in the country's reliance on foreign workers, 
who now form one-third of the total population of the country (Edgar, Azhar, \& Duncan, 2016). In order to reduce the unemployment among Saudis, the Saudi government took some steps in the last two decades to replace the foreign workers with skilled and educated Saudis through the Saudization program (Al-Asfour \& Khan, 2014; Nurunnabi, 2017). Complementing the Saudization program, a recently launched Nitaqat program required all companies to have at least $30 \%$ of their workforce comprised of Saudi nationals (Koyame-Marsh, 2016). Failure to comply with the Nitaqat program results in several punitive consequences, such as the denial of new work visas, the nonrenewal of existing visas for foreign workers, hefty fines, and a restriction of business activities for the firm. Also, the Saudi government recently introduced KSA Vision-2030 (Saudi Vision 2030, 2017), which aims to move from an oil-based economy to a knowledge-based economy, and strictly implement the Saudization program to replace the foreign workers with Saudis (Al-Asfour \& Khan, 2014; Nurunnabi, 2017). Under the KSA Vision-2030, several measures have been taken to discourage organizations from recruiting foreign workers, e.g., fixing their ratio in organizations, not renewing their job contracts, and imposing a progressive tax on dependents living with them in the KSA. These measures have created uncertainty among foreign workers regarding their job security and have instilled a fear of being replaced by local Saudis.

A large number of foreign workers from diverse sociocultural backgrounds and punitive treatments for organizations failing to comply with the Saudization programs have given rise to very complicated working relationships in Saudi firms. For example, Vision-2030 encourages Saudi organizations to promote knowledge sharing among their employees by establishing knowledge management centers. However, it also makes employees, mainly foreign workers, aware of the potential role of their knowledge in securing their jobs. Furthermore, not only foreign workers tend to use their knowledge as a deterrent against Saudization program, but local Saudis 
holding managerial positions are also inclined to keep their knowledge to themselves to avoid being replaced by more talented Saudi subordinates (Alshanbri et al., 2015; Alshanbri, Maqsood, \& Khalfan, 2016). For example, the findings of a recently conducted qualitative study by Yeo and Marquardt (2015) suggest that despite establishing knowledge management centers, both Saudi and foreign employees tend not only to avoid knowledge sharing but also to hide knowledge from others, particularly those in managerial positions. The initiatives being taken under KSA Vision2030 and the intricate working relationships within Saudi organizations make a very strong case for the exploration and comparison of the consequences of SKH for locals (i.e., Saudis) and foreign employees working in the KSA.

\section{Knowledge Hiding}

According to Davenport and Prusak (1998), knowledge is "a fluid mix of framed experience, values, contextual information, and expert insights that provides a framework for evaluating and incorporating new experiences and information" (p. 5). Knowledge sharing plays a central role in effective knowledge management, where knowledge can be transferred among knowledge holders and seekers. Substantial empirical evidence produced over the last two decades suggests that employee knowledge-sharing behavior is related to a wide range of positive work-related outcomes, such as individual performance (Quigley, Tesluk, Locke, \& Bartol, 2007), team creativity and innovation (Cheung, Gong, Wang, Zhou, \& Shi, 2016; Dong, Bartol, Zhang, \& Li, 2017), and organizational financial performance (Andreeva \& Kianto, 2012). However, despite these benefits, many employees do not engage in knowledge sharing for various reasons, such as a self-referenced fears of losing face, losing power, and being isolated (Fang, 2017), or an apprehension of being evaluated (Bordia, Irmer, \& Abusah, 2006); instead, they tend to engagein 
knowledge hiding, impairing the knowledge-sharing process in organizations (Connelly et al., 2012).

Knowledge hiding refers to "an intentional attempt by an individual to withhold or conceal knowledge that has been requested by another person" (Connelly et al., 2012; p. 65). Although there may be some conceptual overlap between knowledge hiding and similar constructs, e.g., knowledge sharing and knowledge hoarding, knowledge hiding is distinct from these similar constructs in at least two ways (Connelly et al., 2012). First, knowledge hiding captures one's intentional attempt to hide knowledge from someone who has requested it, whereas, in both knowledge sharing and knowledge hoarding, it is not necessary for someone to request knowledge. Second, these similar constructs are not as broad as knowledge hiding, which is a higher-level construct with three sub-dimensions, i.e., evasive hiding, playing dumb, and rationalized hiding, capturing the different ways in which knowledge hiding occurs (Connelly et al., 2012). In evasive hiding, the hider provides incorrect information or makes the false promise of providing complete information in the future, but with no such intention. In playing dumb, the hider pretends to be ignorant of the relevant knowledge, and in rationalized hiding, the hider either presents a justification of being unable to provide the knowledge or blames another party for failing to provide the requested knowledge (Connelly et al., 2012).

Considering these dimensions, researchers have recently begun to explore the negative consequences of knowledge hiding in organizations, such as less psychological safety; less thriving, creative and innovative individual and team behaviors; more voluntary turnover intentions; hurt relationships; and reciprocal knowledge hiding (Bogilović, Černe, \& Škerlavaj, 2017; Černe et al., 2017; Černe et al., 2014; Connelly \& Zweig, 2015; Fong, Men, Luo, \& Jia, 2018; Jiang, Hu, Wang, \& Jiang, 2018; Serenko \& Bontis, 2016). Although these consequences 
are based on knowledge hiding between two coworkers, "this is not to imply that supervisors never hide knowledge [from supervisee]" (Connelly et al., 2015; p. 488); rather, the consequences of such top-down knowledge hiding are still to be explored. In fact, there are multiple reasons to argue that supervisors do hide knowledge from their supervisees. For example, supervisors have earned the supervisory role due to their control over the specific work-related knowledge that their supervisees may not have. Thus, supervisors' psychological ownership of their knowledge and their fears of losing power, being taken advantage of, and being exploited by their supervisees can lead to SKH.

This is particularly true in the complex and uncertain job market of the KSA, which has resulted in employees being skeptical about the true intentions of others' conduct in the organization (Skok \& Tahir, 2010; Yeo \& Marquardt, 2015). In this ambiguous situation, supervisors' control over work-related expert knowledge, which they have acquired or developed by investing considerable effort over an extended period, becomes a crucial factor determining their job security and career progression in the organization (Peng, 2013). Therefore, we argue for the existence of SKH in the context of the KSA and explore its effect on supervisee pro-social behavior, i.e., OCB-S.

\section{Supervisor Knowledge Hiding (SKH) and Supervisee Organizational Citizenship Behavior Directed Toward a Supervisor (OCB-S)}

Organ (1988) defines OCB as a "behavior that is discretionary, not directly or explicitly recognized by the formal reward system and that in aggregate promotes the effective functioning of the organization" (p. 4). Over the years, several dimensions of OCB, e.g., altruism, courtesy, and conscientiousness, have emerged in the organizational behavior literature. However, Williams and 
Anderson (1991) suggested dimensions, i.e., OCB toward individuals (OCB-I) and OCB toward the organization (OCB-O), have been the most popular dimensions of OCB (Arain, Sheikh, Hameed, \& Asadullah, 2017; Newman, Schwarz, Cooper, \& Sendjaya, 2017; Podsakoff et al., 2009). In further categorizing OCB, Masterson et al. (2000) introduced a third category, supervisor-directed OCB (i.e., OCB-S) - supervisees' participation in extra-role work activities to support their supervisor above and beyond the call of duty - and suggested it as a more relevant category of OCB when measuring the effect of supervisor behavior (e.g., interactional justice) on supervisees' prosocial behavior. Building on social exchange theory (Blau, 1964), Masterson et al. (2000) suggested that supervisees' perception of interactional justice bytheir supervisors has a significant positive association with supervisees' OCB-S.

Social exchange theory (Blau, 1964), in conjunction with the norm of reciprocity (Gouldner, 1960), has been used as a leading theoretical framework to understand the effect of leader/supervisor behavior on follower/supervisee attitudes and behaviors (Shore, Coyle-Shapiro, Chen, \& Tetrick, 2009). Following this theoretical framework, extant research on leaderfollower/supervisor-supervisee relationship suggests that positive leader/supervisor behavior, e.g., leader-member exchange (LMX), ethical leadership, and servant leadership, motivates followers/supervisees to reciprocate positive leader/supervisor behavior by increasing their OCBs until a perceived balance of exchange is reached (Hoch, Bommer, Dulebohn, \& Wu, 2016; Newman et al., 2017). On the other hand, negative leader/supervisor behavior, e.g., abusive supervision, motivates followers/supervisees to negatively reciprocate leader/supervisor behavior by decreasing their OCBs until a perceived balance of exchange is reached (Mackey, Ellen, Hochwarter, \& Ferris, 2013). Prior research suggests that abusive supervision and self-serving leadership (Mackey et al., 2017; Peng et al., 2018) are unethical supervisory behaviors that foster 
manipulative and unethical supervisee behaviors through the supervisors' reward-punishment and role modeling capacity.

In further extending this work, we argue that $\mathrm{SKH}$, i.e., the supervisor either deceives his/her supervisees - provides them with incorrect knowledge (evasive hiding) or acts ignorant of the required knowledge (playing dumb) - or gives them a justification by blaming others for failing to provide the required knowledge (rationalized hiding), is an unethical supervisory behavior for two reasons. First, SKH is an unethical behavior as supervisors through their role modeling capacity foster a culture of deception and compromise on professional duties in the workplace. Second, in the knowledge management literature, a supervisor is suggested as a legitimate source and facilitator of knowledge (Mary MacNeil, 2004). By deceiving and deliberately not sharing the knowledge expected of them, supervisors put at stake the legitimacy of social exchange in the workplace, which is primarily based on trust as not all of the duties can be put into writing.

Consequently, SKH motivates supervisees to reduce their OCB-S ${ }^{2}$ to balance the negative social exchange with their supervisors. For example, when a supervisee perceives that his/her supervisor hides knowledge from him/her, then he/she tends to balance the negative social exchange with the supervisor by reducing his/her OCB-S, e.g., not voluntarily helping the supervisor when he/she has a heavy workload and not sharing useful information with the supervisor. Thus, we hypothesize the following relationship.

\footnotetext{
${ }^{2}$ Prior research on the consequences of employee knowledge hiding mostly focused on 'reciprocal knowledge hiding' and recently focused on 'counter productive work behavior' (CWB), as one of the most likely reactions of the victim of knowledge hiding against the culprit of knowledge hiding (Černe et al., 2017; Černe et al., 2014; Connelly \& Zweig, 2015; Serenko \& Bontis, 2016). However, given (1) the supervisory powers for punishing a supervisee who engages in negative work behavior, particularly toward the supervisor, and (2) the work context of the KSA, which is characterized by high uncertainty, low job security, a high-power-distance societal culture, and discrimination between locals and foreigners, it is expected that supervisees react against SKH by reducing their extra-role OCB-S rather than engaging in reciprocal knowledge hiding from and CWB toward their supervisors.
} 


\section{H1. SKH is negatively associated with supervisee OCB-S}

To fully understand the relationship between SKH and supervisee OCB-S, it is potentially significant to examine the underlying motivational mechanism maintaining the relationship. For this purpose, we again take the lead from social exchange theory (Blau, 1964) and explore distrust in supervisor as the mediator between SKH and supervisee OCB-S.

\section{The Mediation of Distrust between SKH and Supervisee OCB-S}

The supervisee's distrust/trust in the supervisor refers to supervisee's confident expectations of the supervisor's negative/positive conduct (Lewicki et al., 1998). Prior empirical studies have confirmed that trust and distrust are not two sides of the same coin; rather, they are independent of each other and can coexist simultaneously (Cho, 2006; Dimoka, 2010; McKnight \& Chervany, 2001; McKnight, Kacmar, \& Chaudhry, 2004). Following social exchange theory, the findings of prior empirical studies on the supervisor-supervisee relationship suggest that supervisees' perception of a positive/negative supervisory treatment engenders trust/distrust, respectively, in a supervisor (Liao \& Chun, 2016; Shore et al., 2009). However, in the case of supervisees' perceptions of negative supervisory behavior (e.g., strict observational monitoring), distrust in a supervisor is a more likely reaction (Liao \& Chun, 2016).

Given that this studyfocuses on SKH, we examine distrust in supervisor as the underlying mechanism through which SKH translates into reduced supervisee OCB-S. Specifically, we argue that SKH induces distrust in supervisees, which in turn, motivates supervisees to balance the negative social exchange with the supervisor by reducing their OCB-S. A supervisee's perceptions of evasive hiding (e.g., a supervisor agreed to help but instead gave information different from what was required), and playing dumb by a supervisor (e.g., a supervisor pretended that he/she did 
not have the capacity to provide the required knowledge, even though this was not true) signal to the supervisee that his/her supervisor does not trust him/her. Consequently, the supervisee starts distrusting his/her supervisor and subsequently reduces his/her OCB-S. This is consistent with the arguments presented by Černe et al. (2014) that an act of knowledge hiding by individual 1 from individual 2 motivates individual 2 to start distrusting individual 1 and to restore the balance in the social exchange with individual 1. Furthermore, the qualitative findings of Yeo and Marquardt (2015) highlight distrust in a supervisor as the consequence of SKH in the context of Saudi Arabia. Thus, we hypothesize the following relationships.

H2. SKH is positively associated with supervisee distrust in a supervisor.

H3. Distrust in a supervisor is negatively associated with supervisee OCB-S.

H4. Distrust in a supervisor mediates the negative association between SKH and supervisee OCB-S.

In order to fully explore the relationship between SKH and supervisee OCB-S in the complex working relationships between locals (i.e., Saudis) and foreign employees in the KSA, in the next section, we probe the differences in the relationships hypothesized in $\mathrm{H} 1$ to $\mathrm{H} 4$ across the subsamples of local (i.e., Saudis) and foreign employees.

\section{Saudi versus Foreign Employees}

Social exchange theory (Blau, 1964), in conjunction with the norm of reciprocity (Gouldner, 1960), suggests that foreign employees tend to enjoy less positive social exchanges at their workplace - e.g., limited duration work visas with less job security and fewer financial benefits, limited career development and voice opportunities against supervisory abuse - than their local counterparts (Al Ariss, 2014; Ang et al., 2003). For example, using a research sample from 
Singapore, Ang et al. (2003) highlighted that foreign workers have lower distributive justice judgments, $\mathrm{OCB}$, and performance than local workers. Similarly, using a research sample from UAE, Skok and Tahir (2010) highlighted that $80 \%$ of the surveyed participants reported that Arab workers were preferred over foreign workers for training purposes; $97 \%$ perceived that knowledge sharing occurred through informal verbal communication, mostly between Arab colleagues; and 93\% perceived that Arab national culture discourages knowledge sharing, particularly with nonArabs. Furthermore, the findings of a recently published qualitative study by Yeo and Marquardt (2015), in which $85 \%$ of the participants were foreign workers, highlighted that Saudiemployees, particularly those in a supervisory role, considered foreign employees inferior to them and not worthy of knowledge sharing.

Given the aforementioned differences in foreign and local workers' social exchanges with their employers or agents of the employers, i.e., supervisors (Shore et al., 2009), the way these two groups of employees tend to balance their positive/negative exchange relationships may also differ. For example, when perceiving SKH, foreign workers may exhibit more distrust in their supervisor than their Saudi counterparts (Yeo \& Marquardt, 2015).

Moreover, the growing emphasis on the Saudization program has created uncertainty among foreign workers about their job security. The job market for foreign workers in Saudi Arabia is shrinking. Therefore, it is likely that, despite SKH and the resulting distrust in supervisors, foreign workers will not reduce their OCB-S to the extent that their supervisors take notice of it and make them pay for it. This consciousness for safety and job security is evident in the qualitative findings of Yeo and Marquardt (2015), such as "I often keep my mouth shut in meetings because there's no point trying to say something that may work to my disadvantage. I'd rather stay safe and let others sort out the politics and get their hidden agendas out” (p. 318). 
Consistent with these findings, we suggest that foreign employees may reduce their OCB-S, resulted from SKH and subsequently increased distrust, to a lesser extent than their Saudi counterparts. Taken together, we hypothesize the following relationships.

H5. The hypothesized relationships (i.e., H1 to $\mathrm{H4}$ ) will differ significantly in the foreign and Saudi subsamples, such that H1, H3, and H4 are weaker for foreign workers and

H2 is stronger for foreign workers than for Saudi workers.

\section{METHODS}

\section{Sample and Procedure}

Using a convenience sampling and a supervisor-supervisee dyadic design, the data were collected, by distributing hard copies of two different types of research questionnaires, i.e., one for the supervisor and one for his/her supervisee, from employees of 41 domestic and multinational companies. These organizations were operating in both the public and private sectors of Saudi Arabia. Since we aimed to gather data from both Saudi and foreign workers, the questionnaires were prepared in both English and Arabic. The Arabic translation of the employed measures from the original language (i.e., English) was carried out using both a forward (English into Arabic) and backward (Arabic into English) translation method. For this purpose, we hired the services of professional bilingual translators working at one of the coauthor's university's language and translation center. The supervisors' questionnaire consisted of measures of their supervisee's

OCB-S. The supervisees' questionnaire consisted of the measures of SKH and distrust in their supervisor. The two questionnaires were assigned similar codes for later pairing. The use of twosourced data provides a better assessment of the constructs by ruling out the threat of common method variance and self-reported biases (Podsakoff, MacKenzie, \& Podsakoff, 2012). 
We employed undergraduate business students to distribute 560 supervisor-supervisee questionnaires. The data enumerators first contacted employees, who completed the 'supervisee' questionnaire and identified the name of their supervisors. Following this, the enumerators contacted the referred supervisors to fill in the 'supervisor' questionnaire. Once received, both questionnaires were matched using similarity codes, which were then removed during the data entry process to ensure the anonymity and confidentiality of the respondents. It is important to mention that each supervisor was required to fill in the 'supervisee' questionnaire for only one of his/her supervisees. This procedure was followed (1) to avoid putting an undue burden on supervisors to complete questionnaires for multiple employees as it might have affected the quality of supervisors' response, and (2) to rule out the possibility of within-group difference in OCB-S ratings for multiple employees rated by the same supervisor.

Of the 560 total distributed supervisor-supervisee questionnaires, 342 dyads were returned, i.e., the response rate was $61 \%$. After discarding the 25 cases with mismatched dyads and missing values, the remaining 317 supervisor-supervisee matching dyads were used to assess the hypothesized model. Respondents' names were erased during the data entry process to ensure anonymity. Of the 317 participating supervisors, 216 (68\%) were Saudi and 101 (32\%) were foreign. Whereas, of the 317 participating supervisees, $183(58 \%)$ were Saudi and 134 (42\%) were foreign.

Saudi Sample: Among the Saudi supervisors, $77 \%$ were male and 23\% were female, the average age was 38 years, and the average experience was 3 years. Among the Saudi supervisees, $60 \%$ were male and $40 \%$ were female; the average age was 31 years, the average experience was 4.6 years, and the average tenure under the current supervisor was 2.8 years. 
Foreign Sample: Among the foreign supervisors, $81 \%$ were male and 19\% were female, the average age was 38 years, the average experience was 5.85 years. Among the foreign supervisees, $78 \%$ were male and $22 \%$ were female, the average age was 33 years, the average experience was 5.85 years, and the average tenure under the current supervisor was 3.8 years.

\section{Measures}

All the questions were measured on a scale ranging from 1 (not at all) to 7 (to a great extent).

SKH was measured using a 12-item scale developed by Connelly et al. (2012). This scale consists of four items each for evasive hiding, playing dumb, and rationalized hiding. The scale opens with the following statement: "For a moment, visualize in your mind your supervisor, who receives a knowledge request from you: how does he/she behave?" A sample item of evasive hiding is as follows: "My supervisor agrees with me but never really intends to provide me with the requested information." A sample item of playing dumb is as follows: "My supervisor says that he/she does not know, even though he/she does." A sample item of rationalized hiding is as follows: "My supervisor explains that the information is confidential and only available to authorized people." The alpha reliability values of these subscales of SKH in this study are 0.94 for evasive hiding, 0.93 for playing dumb, and 0.94 for rationalized hiding.

Distrust in supervisor was measured using a 5-item scale developed by McAllister, Lewicki, and Bies (2000) and further validated by Liao and Chun (2016). A sample item is as follows: "Whenever possible, my supervisor takes advantage of me." The alpha reliability value for this scale is 0.94 .

$O C B-S$ was adapted from the 7-item scale of individual-directed OCB developed by Williams and Anderson (1991). The supervisor assessed his/her supervisee's OCB-S behavior. A 
sample item is the following: "He/she voluntarily helps me when I have a heavy workload." The alpha reliability value for this scale is 0.92 .

We also controlled for the effects of the participants' organization, gender, age, experience, supervisor-supervisee relationship tenure, and supervisor's nationality (i.e., Saudi/foreign) on supervisee's OCB-S (Podsakoff et al., 2009; Podsakoff, MacKenzie, Paine, \& Bachrach, 2000).

Table 1 presents the mean, standard deviation, and intercorrelations of SKH (i.e., evasive hiding (EH), playing dumb (PD), and rationalized hiding ( $\mathrm{RH})$ ), distrust, as well as OCB-S.

Insert table 1 about here

\section{Analysis and Results}

The hypothesized research model was tested by using PLS-SEM (Hair Jr et al., 2016; Lohmöller, 1989) with the statistical software SmartPLS 3 (Ringle et al., 2015). The hypothesized model was tested by following a two-step data analysis approach, i.e., in the first step, we assessed the measurement model to confirm the factorial validity of the employed measures, and in the second step, we assessed a structural model to test the hypothesized relationships.

\section{Measurement Model}

We assessed SKH, which has been conceptualized as a combination of evasive hiding, playing dumb, and rationalized hiding (Connelly et al., 2012), using one factor higher-order formative construct, whereas the rest of the unidimensional latent constructs, i.e., distrust in supervisor and OCB-S, were assessed using first-order reflective measurement models (refer to Figure 1). The adequacy of these measurement models was assessed for composite reliability, convergent validity, and discriminant validity. According to Hair, Black, Babin, and Anderson (2010), 
composite reliability (CR) is established when the loadings of indicators of a latent construct are higher than 0.7 ; convergent validity is established when the average variance extracted (AVE) is greater than 0.5. Except for OCB-S (i.e., 0.68), the AVE value of all the measures was above 0.80, and the CR value of all the measures was above 0.90 . Thus, all the measures fulfilled the criteria of composite reliability and convergent validity.

Insert figure 1 about here

Furthermore, to establish discriminant validity, we used the heterotrait-monotrait(HTMT) ratio of the correlations method, which has recently been established as a superior criterion over the traditional Fornell-Larcker method for assessing discriminant validity, with a maximum threshold of 0.85 (Henseler, Ringle, \& Sarstedt, 2015; Rasoolimanesh, Ringle, Jaafar, \& Ramayah, 2017). The results of the $\mathrm{HTMT}_{85}$ ratio (refer to Table 2) showed that all the employed measures had a value of less than 0.85 ; therefore, discriminant validity was also established.

Insert table 2 about here

\section{Hypotheses Testing}

We tested hypotheses H1-H4 in the structural model by assessing the significance (p-value) of the structural paths between the latent variables. The results (Table 3) indicated that SKH had a significant and negative (total) effect on OCB-S (path coefficient $=-0.225, \mathrm{p}<0.001$ ); thus, H1 was supported by the results. The results also showed that SKH had a significant and positive association with distrust in one's supervisor (path coefficient $=0.512, \mathrm{p}<0.001$ ), which then had a significant and negative association with OCB-S (path coefficient $=-0.181, \mathrm{p}<0.01$ ); thus, H2 
and $\mathrm{H} 3$ were also supported. H4, regarding the indirect effect of SKH on OCB-S via distrust in the supervisor, was also supported by the results (path coefficient $=-0.093, \mathrm{p}<0.01$ ); however, it was a partial mediation, as the direct effect of SKH on OCB-S was still significant (path coefficient = $-0.162, \mathrm{p}<0.05)$

Insert table 3 about here

\section{Multigroup Analysis}

An MGA was also performed using a two-step analytical procedure. First, we assessed the invariance of the measurement models using measurement invariance of composites (MICOM) method (Henseler, Ringle, \& Sarstedt, 2016) to establish measurement invariance for the measurement models of Saudi and foreign subsamples. MICOM method consists of three steps: in the first step, configural invariance is assessed; in the second step, the establishment of compositional invariance is assessed; and in the third step, equal means and variance is assessed. For the first step, we used the same measurement model, as tested above, for both Saudi and foreign groups using identical algorithm settings. In this way, the first step of the MICOM method regarding configural invariance was established. To establish the remaining two steps of MICOM, we ran the permutation procedure with 5000 permutations and a 5\% significance level for both groups. In step 2, we compared the original composite score correlations (c) with the composite score correlations obtained from the permutation procedure $\left(c_{u}\right)$. The results (Table 4$)$ established the compositional invariance between the two groups. Lastly, we assessed the equality of means and variance between the two groups.

The results established the full measurement invariance for rationalized hiding (RH) and OCB-S, with partial measurement invariance for evasive hiding (EH), playing dumb (PD), and 
distrusting one's supervisor. According to Henseler et al. (2016), when partial or full measurement invariance is established, then it is proper to assess the invariance of the structural model to examine whether the groups are different in their path coefficients.

Insert table 4 about here

We proceeded to assess the differences between the path coefficients of the structural models of the two groups using Henseler, Ringle, and Sinkovics (2009) boot-strap-based MGA, which has been recently established as the most conservative MGA method for PLS-SEM (Rasoolimanesh et al., 2017; Schlägel \& Sarstedt, 2016). The results (refer to Table 5) showed that Saudi and foreign employees significantly differ on the path from $\mathrm{SKH} \rightarrow$ distrust $(\mathrm{H} 2)$, as the coefficient was significantly stronger for foreigners $(0.598 * * *)$ than for Saudis $(0.432 * * *)$. However, no significant difference was established in the coefficients for H1, H3, and H4. Thus, H5 was partially supported by the results. It is interesting to note that although MGA revealed no significant differences in Saudi and foreign employees for H1 (SKH $\rightarrow$ OCB-S), H3 (distrust $\rightarrow$ $\mathrm{OCB}-\mathrm{S})$, and $\mathrm{H} 4(\mathrm{SKH} \rightarrow$ distrust $\rightarrow$ OCB-S), the path coefficients of these relationships were stronger for Saudi employees (H1: $-0.320 * * *, H 3:-0.210^{* *}$, \& H4: $\left.-0.091 *\right)$ than for foreign employees (H1: -0.214*, H3: -0.193ns, \& H4: -0.115ns).

Insert table 5 about here

\section{DISCUSSION}

This study aimed to extend the prior understanding of knowledge hiding by examining the existence and consequences of SKH in the context of the Middle East, in particular in the KSA. 
Building on social exchange theory, we first examined the direct and indirect relationships, via distrust in a supervisor, between SKH and supervisee OCB-S. In the second step, we conducted an MGA to examine the difference in these relationships across local (i.e., Saudi) and foreign subsamples. The PLS-SEM-based results of this study provided full support for the first part and partial support for the second part. More specifically, in providing support for $\mathrm{H} 1$, the results showed that SKH had a significant and negative association with supervisee OCB-S. The results for $\mathrm{H} 2$ and $\mathrm{H} 3$ showed that SKH had a significant and positive association with distrust in one's supervisor, which then had a significant and negative association with supervisee OCB-S. Lastly, the results for $\mathrm{H} 4$ showed that distrust in the supervisor significantly mediated the direct negative association between SKH and supervisee OCB-S.

\section{Theoretical Implications}

To the best of our knowledge, this is the first study to examine the existence and consequences of knowledge hiding in a supervisor-supervisee relationship (i.e., SKH) in the relatively unexplored and complicated work context of the KSA. Prior research on knowledge hiding suggests that the victims of knowledge hiding react to the perpetrator by engaging in reciprocal knowledge hiding (Černe et al., 2014; Connelly \& Zweig, 2015; Serenko \& Bontis, 2016). In the context of SKH, it is logical to expect that supervisees react to $\mathrm{SKH}$ by reducing their OCB-S. Our finding is consistent with the leadership-OCB literature, suggesting that negative and unethical supervisory treatment, such as abusive supervision, motivates supervisees to reduce their OCB to restore balance in their negative social exchange with their supervisors (Mackey et al., 2017).

Drawing upon social exchange theory and the norm of reciprocity, this study revealed not only the significant negative association between SKH and supervisee OCB-S but also how this 
relationship is mediated by distrust in one's supervisor, which served as the underlying motivational mechanism maintaining this relationship. The mediation effect of distrust in one's supervisor between SKH and supervisee OCB-S is also consistent with both the knowledge-hiding and OCB literatures. For instance, Černe et al. (2014) suggest that an employee's experience of knowledge hiding by another employee first engenders a feeling of distrust, which in turn motivates the victim to engage in reciprocal knowledge hiding from the culprit of the knowledge hiding. The mediation of distrust between the negative supervisory treatment and OCB relationship has also been supported in the leadership-OCB literature. For instance, Wu, Huang, Li, and Liu (2012) highlight that supervisees' perception of perceived interactional justice by their benevolent supervisor first provokes a feeling of trust in the supervisor, which then motivates supervisees to increase their OCB, whereas supervisees' perception of negative supervisory behavior (e.g., strict observational monitoring) stimulates a feeling of distrust in the supervisor, which in turn motivates supervisees to reduce their positive work behavior, i.e., OCB-S (Liao \& Chun, 2016).

An MGA of this study highlighted that the consequences of SKH, particularly distrust in one's supervisor, in the complex work context of the KSA were not the same for Saudi nationals and foreign employees. Foreign workers showed more distrust in the supervisor but smaller decreases in their OCB-S, whereas Saudi employees showed less distrust but larger decreases in their OCB-S. Specifically, the data partially supported H5 regarding the MGA of Saudi and foreign employees for the relationships hypothesized in H1 to H4. Significant differences between Saudi and foreign subsamples was recorded only for $\mathrm{H} 2$, in which the significant and positive association between SKH and distrust in the supervisor was significantly stronger for foreign workers than for Saudis. This finding is in line with the qualitative study of Yeo and Marquardt (2015) and the 
descriptive survey of Skok and Tahir (2010), which highlighted that foreign employees perceived knowledge hiding and distrust in their supervisors more than their Saudi counterparts.

Furthermore, although the MGA did not show a statistically significant difference for H1, $\mathrm{H} 3$, or $\mathrm{H} 4$, the direction and coefficient size for these relationships showed that foreign workers reduced their OCB-S less than their Saudi counterparts. This is again consistent with the qualitative findings of Yeo and Marquardt (2015), who highlighted lower or nonexistent job security among foreign workers resulting from the Saudization program. Accordingly, we argue that, despite SKH and the subsequent distrust in supervisor, foreign workers might still be trying to remain in their supervisors' good graces by engaging in OCB-S to save their jobs.

Overall, these findings make valuable contributions to the prior knowledge-hiding literature. By using a research sample from Saudi Arabia and conducting an MGA of locals (Saudis) and foreign workers, this study comprehensively addressed the research calls of Connelly and Zweig (2015), to examine the (1) knowledge hiding that occurs between supervisor and supervisee and (2) association between knowledge hiding and OCB. Additionally, employing supervisor-supervisee dyadic data, rigorous data analysis in PLS-SEM, and some recently developed advanced analytical techniques, i.e., HTMT, MICOM, and MGA, represent a significant methodological contribution of this paper to the knowledge-hiding literature.

\section{Practical Implications}

The results of this study have useful practical implications for managers in terms of understanding the existence and consequences of SKH in organizations, particularly organizations in the Middle East. Specifically, our results remind supervisors that their knowledge hiding may backfire and increase supervisees' feelings of distrust, which then decreases supervisees' OCB-S. Prior OCB 
research has suggested that a supervisor's success often depends on the extent to which his/her supervisees are motivated to exhibit OCB-S. For instance, assisting a (fresh) supervisor in doing some of his/her supervisory duties, helping him/her learn quickly, passing him/her useful information that he/she himself/herself may not collect, and providing socio-emotional support to $\mathrm{him} /$ her when he/she is down are some examples of how a supervisee's OCB-S can be valuable to his/her supervisor. It is crucial for supervisors to avoid creating any perception of SKH by their supervisees, as this can result in distrust and reduced OCB-S.

Furthermore, prior research on the 'trickle-down' effect of supervisory behavior (Mawritz, Mayer, Hoobler, Wayne, \& Marinova, 2012; Mayer, Kuenzi, Greenbaum, Bardes, \& Salvador, 2009) suggests that supervisees' perceptions of unethical supervisory behavior, i.e., abusive supervision, motivate them to exhibit the same unethical behavior towards others. Following these findings, it can be inferred that supervisees' perceptions of SKH can stimulate them to exhibit the same unethical behavior towards the supervisors and the co-workers. Thus, our findings suggest supervisors be the ethical role models for their supervisees by exhibiting knowledge sharing and refraining from knowledge hiding behaviors. To achieve this goal, HR managers should implement nondiscriminatory HR policies and procedures that facilitate a one-on-one communication channel between the supervisor and each supervisee, which could be quite useful in building a positive image and subsequent trust in supervisors by supervisees, which is an essential condition for the knowledge sharing behavior.

This is particularly true in the case of foreign workers working in the Middle East, who often complain about discriminatory supervisory behavior between Saudi and non-Saudi employees (Skok \& Tahir, 2010; Yeo \& Marquardt, 2015). The results of the MGA in our study also confirm that foreign supervisees reacted to SKH by showing distrust in supervisors more than 
their local Saudi counterparts. Thus, we suggest that managers pay attention to this aspect of work life and implement fair and equitable HR policies for both local (Saudi) and foreign employees. According to Metcalfe and Murfin (2012), the KSA relies on a large foreign workforce due to the lack of a skillful local workforce. The pressure has increased to train this local workforce, as the country is facing challenges in establishing equal employment opportunities to establish

sustainable industries.

Furthermore, to minimize the existence of SKH, it is essential for top management to pay attention to those factors that motivate supervisors to hide knowledge from their supervisees, i.e., a fear of losing power, losing face, and exploitation (Fang, 2017); a lack of psychological safety; and an uncertain work context and policies (Yeo \& Marquardt, 2015). This can be achieved by designing and implementing human resource planning strategies that foster a sense of both psychological and actual job security among local and foreign employees. Such policies would motivate employees to assume collective ownership of the knowledge creation and dissemination processes in their organizations.

\section{Limitations and Future Research}

Albeit this study has several strengths - e.g., use of two-source supervisor-supervisee dyadic data, rigorous and advanced data analysis in PLS-SEM to establish discriminant and convergent validity and measurement and structural invariance before examining the MGA - it also has some limitations. Despite some advantages of PLS-SEM, i.e., a rigorous 3-step procedure to ensure measurement invariance of the hypothesized measurement and structural regression models across local and foreign workers, built-in function of HTMT for ensuring discriminant validity, and a smaller sample size requirement for conducting an MGA, the use of PLS-SEM does have some 
limitations. For example, Hair Jr et al. (2016) state that PLS-SEM does not provide standard goodness-of-fit statistics and the evaluation of model is thus based on its ability to predict the endogenous variable. However, they also suggest that the use of PLS-SEM is preferable when using formative indicators. The results of this study should be interpreted in light of these caveats in mind.

Moreover, the directionality of hypothesized relationships in our model was consistent with the theory and prior knowledge-hiding and OCB literatures. Nevertheless, the use of crosssectional data is not an ideal research design. Future research may replicate our model using a 3wave research design, i.e., measure SKH in time 1, distrust in the supervisor in time 2, and OCB$\mathrm{S}$ in time 3. This time-lagged design would be more accurate in establishing the causal order of the relationships than the inferences made in this study.

Given that this study examined the mediation effect of distrust in a supervisor between SKH and OCB-S, future research might explore other mediating mechanisms, i.e., supervisorbased self-esteem (Landry \& Vandenberghe, 2009). For instance, it could be that SKH first hurts a supervisee's supervisor-based self-esteem, e.g., he/she feels not important or valuable to his/her supervisor, which then motivates him/her to withhold his/her OCB-S, or even some other extrarole positive behavior, i.e., promotive and prohibitive voices (Liang, Farh, \& Farh, 2012). Furthermore, it is very likely that some factors, e.g., psychological safety, the availability of alternative job opportunities, and a knowledge-sharing climate, moderate the direct and indirect relationships between SKH and OCB-S. Replicating the relationships examined in this studywith some of these moderators might better explain the reason for the non-significant direct and indirect effects of SKH on OCB-S for foreign employees. 
Furthermore, drawing from Mawritz et al. (2012) highlighted 'trickle-down' effect of abusive supervision, an exciting extension of our work would be to collect multilevel data on knowledge hiding, i.e., a supervisor's knowledge hiding from a supervisee and a supervisee's knowledge hiding from a coworker, and to examine whether the effect of SKH trickles down to supervisees' knowledge hiding from coworkers.

\section{Conclusion}

This study aimed to answer three important research questions in the knowledge hiding literature, such as how SKH affects supervisee OCB-S, why it affects supervisee OCB-S, and for which employees (i.e., local versus foreign) it affects supervisee OCB-S more. The findings show that SKH was negatively related to employee OCB-S, and this relationship existed partly due to the mediation effect of distrust in one's supervisor, which was first engendered by SKH and led to decreased OCB-S. Furthermore, SKH is found to engender distrust in one's supervisor significantly more for foreign workers than for local workers. The theoretical implications of this study highlight the existence of SKH and its potential positive effects on employees' distrust in their supervisor - which is significantly larger for foreign workers than for local workers - and the subsequent decrease in OCB-S. In terms of managerial implications, these findings provide recommendations for managers to be an ethical role model for their supervisees by exhibiting knowledge-sharing behavior rather than knowledge-hiding behavior, as the latter ultimately negatively affects them through employee increased distrust and decreased OCB-S. 


\section{COMPLIANCE WITH ETHICAL STANDARDS}

- No funding was received for the research used in this study.

- The author's identifying information is on the title page, which is separate from the manuscript.

- Being a first and corresponding author of this article, I declare that there is no conflict of interest related to this article.

- Ethical approval: all the procedures performed in this research/article involving human participants were in accordance with the ethical standards of the institutional and/or national research committee and with the 1964 Helsinki declaration and its later amendments or comparable ethical standards.

- Informed consent was obtained from all the individual participants included in the study.

- This article does not contain any studies with animals performed by any of the authors. 


\section{REFERENCES}

Al-Asfour, A., \& Khan, S. A. (2014). Workforce localization in the Kingdom of Saudi Arabia: Issues and challenges. Human Resource Development International, 17(2), 243-253.

Al Ariss, A. (2014). Voicing experiences and perceptions of local managers: Expatriation in the Arab Gulf. The International Journal of Human Resource Management, 25(14), 19781994.

Alshanbri, N., Khalfan, M., Noor, M. A., Dutta, D., Zhang, K., \& Maqsood, T. (2015). Employees' turnover, knowledge management and human recourse management: a case of Nitaqat program. International Journal of Social Science and Humanity, 5(8), 701.

Alshanbri, N., Maqsood, T., \& Khalfan, M. M. (2016). Mr. Expat, you are fired! Employees' replacement case study from the Middle East. Middle East Journal of Management, 3(1), 49-71.

Andreeva, T., \& Kianto, A. (2012). Does knowledge management really matter? Linking knowledge management practices, competitiveness and economic performance. Journal of Knowledge Management, 16(4), 617-636.

Ang, S., Van Dyne, L., \& Begley, T. M. (2003). The employment relationships of foreign workers versus local employees: A field study of organizational justice, job satisfaction, performance, and OCB. Journal of Organizational Behavior, 24(5), 561-583.

Arain, G. A., Sheikh, A., Hameed, I., \& Asadullah, M. A. (2017). Do as I do: The effect of teachers' ethical leadership on business students' academic citizenship behaviors. Ethics \& Behavior, 27(8), 665-680.

Babcock, P. (2004). Shedding light on knowledge management. HR Magazine, 49(5), 46-51. 
Bavik, Y. L., Tang, P. M., Shao, R., \& Lam, L. W. (2017). Ethical leadership and employee knowledge sharing: Exploring dual-mediation paths. The Leadership Quarterly. 29(2), $322-332$.

Blau, P. M. (1964). Exchange and power in social life. New York: Wiley.

Bogilović, S., Černe, M., \& Škerlavaj, M. (2017). Hiding behind a mask? Cultural intelligence, knowledge hiding, and individual and team creativity. European Journal of Work and Organizational Psychology, 26(5), 710-723.

Bordia, P., Irmer, B. E., \& Abusah, D. (2006). Differences in sharing knowledge interpersonally and via databases: The role of evaluation apprehension and perceived benefits. European Journal of Work and Organizational Psychology, 15(3), 262-280.

Černe, M., Hernaus, T., Dysvik, A., \& Škerlavaj, M. (2017). The role of multilevel synergistic interplay among team mastery climate, knowledge hiding, and job characteristics in stimulating innovative work behavior. Human Resource Management Journal, 27(2), 281299.

Černe, M., Nerstad, C. G., Dysvik, A., \& Škerlavaj, M. (2014). What goes around comes around: Knowledge hiding, perceived motivational climate, and creativity. Academy of Management Journal, 57(1), 172-192.

Cheung, S. Y., Gong, Y., Wang, M., Zhou, L., \& Shi, J. (2016). When and how does functional diversity influence team innovation? The mediating role of knowledge sharing and the moderation role of affect-based trust in a team. Human Relations, 69(7), 1507-1531.

Cho, J. (2006). The mechanism of trust and distrust formation and their relational outcomes. Journal of Retailing, 82(1), 25-35. 
Connelly, C. E., \& Zweig, D. (2015). How perpetrators and targets construe knowledge hiding in organizations. European Journal of Work and Organizational Psychology, 24(3), 479-489.

Connelly, C. E., Zweig, D., Webster, J., \& Trougakos, J. P. (2012). Knowledge hiding in organizations. Journal of Organizational Behavior, 33(1), 64-88.

Cropanzano, R., \& Mitchell, M. S. (2005). Social exchange theory: An interdisciplinary review. Journal of Management, 31(6), 874-900.

Davenport, T. H., \& Prusak, L. (1998). Working knowledge: How organizations manage what they know: Harvard Business Press.

Dimoka, A. (2010). What does the brain tell us about trust and distrust? Evidence from a functional neuroimaging study. MIS Quarterly, 34(2), 1-24.

Dong, Y., Bartol, K. M., Zhang, Z. X., \& Li, C. (2017). Enhancing employee creativity via individual skill development and team knowledge sharing: Influences of dual-focused transformational leadership. Journal of Organizational Behavior, 38(3), 439-458.

Edgar, D., Azhar, A., \& Duncan, P. (2016). The Impact of the Saudization Policy on Recruitment and Retention: A Case Study of the Banking Sector in Saudi Arabia. Journal of Business, $1(5), 01-14$.

Fang, Y.-H. (2017). Coping with fear and guilt using mobile social networking applications: Knowledge hiding, loafing, and sharing. Telematics and Informatics, 34(5), 779-797.

Fong, P. S., Men, C., Luo, J., \& Jia, R. (2018). Knowledge hiding and team creativity: the contingent role of task interdependence. Management Decision, 56(2), 329-343.

Gagné, M. (2009). A model of knowledge- sharing motivation. Human Resource Management, 48(4), 571-589. 
Gouldner, A. W. (1960). The norm of reciprocity: a preliminary statement. American Sociological Review, 25(2), 161-178.

Guzzo, R. A., Noonan, K. A., \& Elron, E. (1994). Expatriate managers and the psychological contract. Journal of Applied Psychology, 79(4), 617-626.

Hair, J. F., Black, W. C., Babin, B. J., \& Anderson, R. E. (2010). Multivariate Data Analysis (7th ed.). Upper Saddle River: NJ: Prentice Hall.

Hair Jr, J. F., Hult, G. T. M., Ringle, C., \& Sarstedt, M. (2016). A primer on partial least squares structural equation modeling (PLS-SEM): Sage Publications.

Henseler, J., Ringle, C. M., \& Sarstedt, M. (2015). A new criterion for assessing discriminant validity in variance-based structural equation modeling. Journal of the Academy of Marketing Science, 43(1), 115-135.

Henseler, J., Ringle, C. M., \& Sarstedt, M. (2016). Testing measurement invariance of composites using partial least squares. International Marketing Review, 33(3), 405-431.

Henseler, J., Ringle, C. M., \& Sinkovics, R. R. (2009). The use of partial least squares path modeling in international marketing. In R. R. Sinkovics \& P. N. Ghauri (Eds.), New challenges to international marketing (pp. 277-319): Emerald Group Publishing Limited.

Hoch, J. E., Bommer, W. H., Dulebohn, J. H., \& Wu, D. (2016). Do Ethical, Authentic, and Servant Leadership Explain Variance Above and Beyond Transformational Leadership? A MetaAnalysis. Journal of Management, 0149206316665461.

Jiang, Z., Hu, X., Wang, Z., \& Jiang, X. (2018). Why do Employees Struggle to Thrive at Work? A Look at the Impact of Knowledge Hiding. Paper presented at the Academy of Management Proceedings. 
Koyame-Marsh, R. O. (2016). Saudization and the Nitaqat programs: overview and performance. Journal of Accounting, 6(2), 36-48.

Landry, G., \& Vandenberghe, C. (2009). Role of commitment to the supervisor, leader-member exchange, and supervisor-based self-esteem in employee-supervisor conflicts. The Journal of Social Psychology, 149(1), 5-28.

Lewicki, R. J., McAllister, D. J., \& Bies, R. J. (1998). Trust and distrust: New relationships and realities. Academy of Management Review, 23, 438-458.

Liang, J., Farh, C. I. C., \& Farh, J. L. (2012). Psychological Antecedents of Promotive and Prohibitive Voice: A Two-Wave Examination. Academy of Management Journal, 55(1), 71-92. doi:10.5465/amj.2010.0176

Liao, E. Y., \& Chun, H. (2016). Supervisor monitoring and subordinate innovation. Journal of Organizational Behavior, 37(2), 168-192.

Lin, C. P. (2007). To share or not to share: Modeling tacit knowledge sharing, its mediators and antecedents. Journal of Business Ethics, 70(4), 411-428.

Lohmöller, J.-B. (1989). Predictive vs. Structural Modeling: PLS vs. ML. In Latent Variable Path Modeling with Partial Least Squares (pp. 199-226): Springer.

Mackey, J. D., Ellen, B. P., Hochwarter, W. A., \& Ferris, G. R. (2013). Subordinate social adaptability and the consequences of abusive supervision perceptions in two samples. The Leadership Quarterly, 24(5), 732-746.

Mackey, J. D., Frieder, R. E., Brees, J. R., \& Martinko, M. J. (2017). Abusive supervision: A metaanalysis and empirical review. Journal of Management, 43(6), 1940-1965.

Mary MacNeil, C. (2004). Exploring the supervisor role as a facilitator of knowledge sharing in teams. Journal of European Industrial Training, 28(1), 93-102. 
Masterson, S. S., Lewis, K., Goldman, B. M., \& Taylor, M. S. (2000). Integrating justice and social exchange: The differing effects of fair procedures and treatment on work relationships. Academy of Management Journal, 43(4), 738-748.

Mawritz, M. B., Mayer, D. M., Hoobler, J. M., Wayne, S. J., \& Marinova, S. V. (2012). A trickledown model of abusive supervision. Personnel Psychology, 65(2), 325-357.

Mayer, D. M., Kuenzi, M., Greenbaum, R., Bardes, M., \& Salvador, R. B. (2009). How low does ethical leadership flow? Test of a trickle-down model. Organizational Behavior and Human Decision Processes, 108(1), 1-13.

McAllister, D., Lewicki, R., \& Bies, R. (2000). Hardball: The impact of trust, distrust, and relationship quality on hard influence tactic use. Unpublished manuscript.

McKnight, D. H., \& Chervany, N. L. (2001). Trust and Distrust Definitions: One Bite at a Time. Lecture Notes in Computer Science, 2246, 27-54.

McKnight, D. H., Kacmar, C. J., \& Chaudhry, V. (2004). Dispositional Trust and Distrust Distrust Distinctions in Predicting High- and Low-Risk Internet Expert Advice Site Perceptions. EService Journal 3(2), 35-58.

Mellahi, K. (2007). The effect of regulations on HRM: private sector firms in Saudi Arabia. The International Journal of Human Resource Management, 18(1), 85-99.

Mesmer-Magnus, J. R., \& DeChurch, L. A. (2009). Information sharing and team performance: A meta-analysis. Journal of Applied Psychology, 94(2), 535.

Metcalfe, B. D., \& Murfin, T. (Eds.). (2012). Leadership, social development and political economy in the Middle East: an introduction. Northampton, MA.: Edward Elgar. 
Meyer, M., Ohana, M., \& Stinglhamber, F. (2017). The impact of supervisor interpersonal justice on supervisor-directed citizenship behaviors in social enterprises: a moderated mediation model. The International Journal of Human Resource Management, 1-22.

Newman, A., Schwarz, G., Cooper, B., \& Sendjaya, S. (2017). How servant leadership influences organizational citizenship behavior: The roles of LMX, empowerment, and proactive personality. Journal of Business Ethics, 145(1), 49-62.

Nurunnabi, M. (2017). Transformation from an Oil-based Economy to a Knowledge-based Economy in Saudi Arabia: the Direction of Saudi Vision 2030. Journal of the Knowledge Economy, 1-29.

Organ, D. W. (1988). Organizational Citizenship Behavior: The Good Soldier Syndrome. Lexington, MA: Lexington Books.

Peng, H. (2013). Why and when do people hide knowledge? Journal of Knowledge Management, 17(3), 398-415.

Peng, J., Wang, Z., \& Chen, X. (2018). Does Self-Serving Leadership Hinder Team Creativity? A Moderated Dual-Path Model. Journal of Business Ethics, 1-15.

Podsakoff, N. P., Whiting, S. W., Podsakoff, P. M., \& Blume, B. D. (2009). Individual- and organizational-level consequences of organizational citizenship behaviors: A metaanalysis. Journal of Applied Psychology, 94(1), 122-141.

Podsakoff, P. M., MacKenzie, S. B., Paine, J. B., \& Bachrach, D. G. (2000). Organizational citizenship behaviors: a critical review of theoretical and empirical literature and suggestions for future research. Journal of Management, 26, 513-532. 
Podsakoff, P. M., MacKenzie, S. B., \& Podsakoff, N. P. (2012). Sources of method bias in social science research and recommendations on how to control it. Annual Review of Psychology, 63, 539-569.

Quigley, N. R., Tesluk, P. E., Locke, E. A., \& Bartol, K. M. (2007). A multilevel investigation of the motivational mechanisms underlying knowledge sharing and performance. Organization Science, 18(1), 71-88.

Rasoolimanesh, S. M., Ringle, C. M., Jaafar, M., \& Ramayah, T. (2017). Urban vs. rural destinations: Residents' perceptions, community participation and support for tourism development. Tourism Management, 60, 147-158.

Riege, A. (2005). Three-dozen knowledge-sharing barriers managers must consider. Journal of Knowledge Management, 9(3), 18-35.

Ringle, C., Wende, S., \& Becker, J. (2015). SmartPLS. Boenningstedt, Germany: SmartPLS GmbH. In.

Saudi Vision 2030. (2017). Saudi Arabia's Vision 2030. Retrieved from http://vision2030.gov.sa/en

Schlägel, C., \& Sarstedt, M. (2016). Assessing the measurement invariance of the fourdimensional cultural intelligence scale across countries: A composite model approach. European Management Journal, 34(6), 633-649.

Serenko, A., \& Bontis, N. (2016). Understanding counterproductive knowledge behavior: antecedents and consequences of intra-organizational knowledge hiding. Journal of Knowledge Management, 20(6), 1199-1224. 
Shore, L. M., Coyle-Shapiro, J. A.-M., Chen, X.-P., \& Tetrick, L. E. (2009). Social exchange in work settings: Content, mixed and process models. Management and Organization Review, 5(3), 289-302.

Škerlavaj, M., Connelly, C. E., Cerne, M., \& Dysvik, A. (2018). Tell me if you can: time pressure, prosocial motivation, perspective taking, and knowledge hiding. Journal of Knowledge Management, 22 (7), 1489-1509.

Skok, W., \& Tahir, S. (2010). Developing a knowledge management strategy for the Arab world. The Electronic Journal of Information Systems in Developing Countries, 41(1), 1-11.

Williams, L. J., \& Anderson, S. E. (1991). Job satisfaction and organizational commitment as predictors of organizational citizenship and in-role behaviors. Journal of Management, 17, $601-617$.

Wu, M., Huang, X., Li, C., \& Liu, W. (2012). Perceived interactional justice and trust- insupervisor as mediators for paternalistic leadership. Management and Organization Review, 8(1), 97-121.

Yeo, R. K., \& Marquardt, M. J. (2015). To share or not to share? Self-perception and knowledgesharing intent. Knowledge Management Research \& Practice, 13(3), 311-328. 
FIGURE 1

\section{The Hypothesized Measurement and Structural Models}

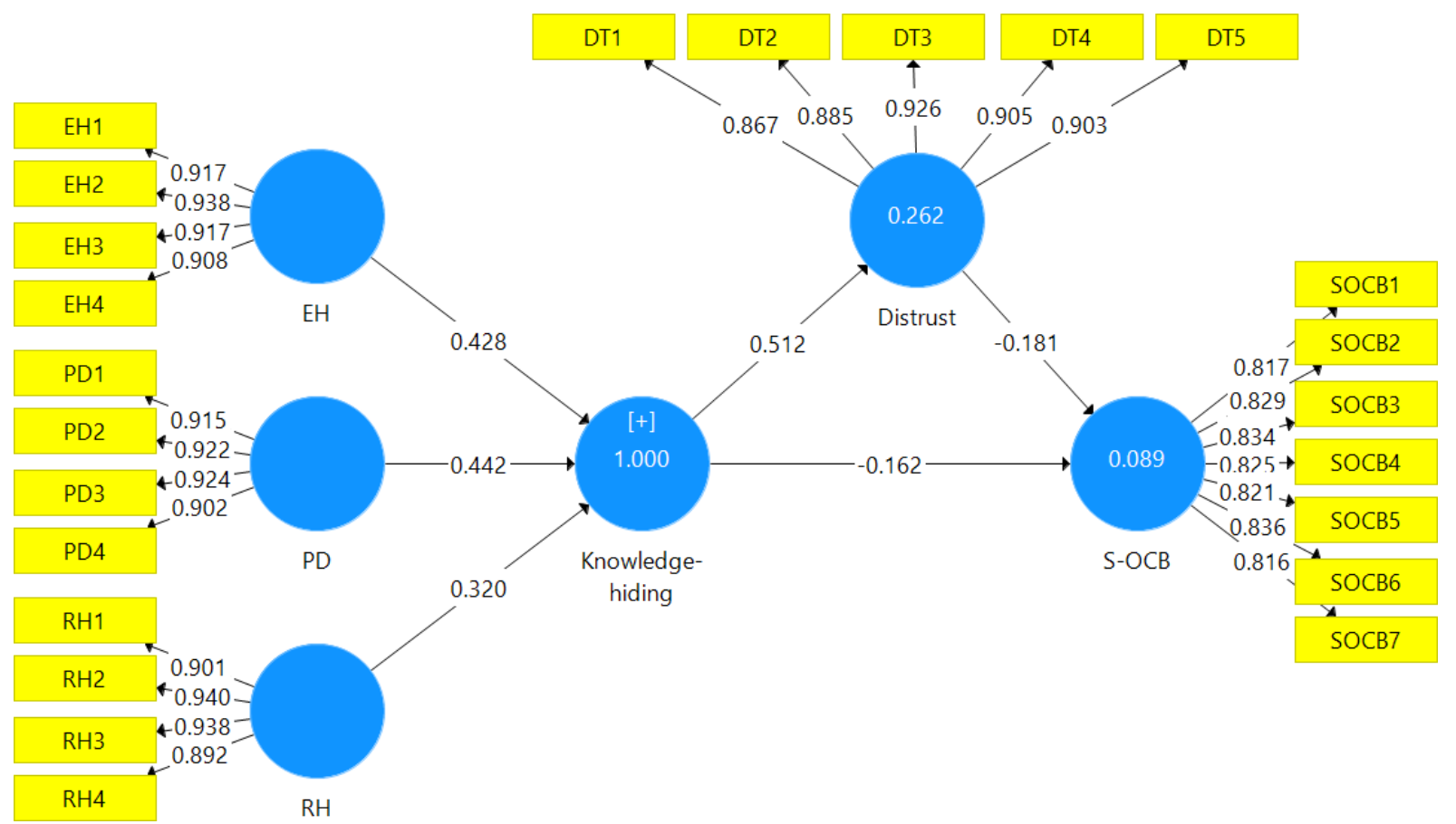


TABLE 1

Descriptive Statistics \& Intercorrelations

\begin{tabular}{|l|l|l|l|l|l|l|l|}
\hline Constructs & Mean & STD & EH & PD & RH & Distrust & OCB-S \\
\hline EH & 2.235 & 1.224 & $\mathbf{0 . 8 4 7}$ & & & & \\
\hline PD & 2.281 & 1.278 & $0.746^{* *}$ & $\mathbf{0 . 8 3 9}$ & & & \\
\hline RH & 3.246 & 1.516 & $0.389^{* *}$ & $0.453^{* *}$ & $\mathbf{0 . 8 4 3}$ & & \\
\hline Distrust & 2.617 & 1.260 & $0.465^{* *}$ & $0.527^{* *}$ & $0.240^{* *}$ & $\mathbf{0 . 8 0 6}$ & \\
\hline OCB-S & 5.057 & 1.174 & $-0.227^{* *}$ & $-0.248^{* *}$ & $-0.134^{*}$ & $-0.259^{* *}$ & $\mathbf{0 . 6 8 2}$ \\
\hline
\end{tabular}

N = 317 (Saudi = 183; Foreign 134); EH = Evasive hiding; PD = Playing dumb; RH = Kationalized hiding; OCB-S represent average variance extracted (AVE) 
TABLE 2

Discriminant Validity (HTMT ${ }_{0.85}$ )

\begin{tabular}{|l|l|l|l|l|l|}
\hline Constructs & EH & PD & RH & Distrust & OCB-S \\
\hline EH & & & & & \\
\hline PD & 0.797 & & & & \\
\hline RH & 0.416 & 0.485 & & & \\
\hline Distrust & 0.495 & 0.561 & 0.256 & & \\
\hline OCB-S & 0.246 & 0.268 & 0.146 & 0.279 & \\
EH = Evasive hiding; PD = Playing dumb; RH = Rationalized hiding; OCB-S = Organizational citizenship behavior
\end{tabular}

directed at supervisor 
TABLE 3

The Hypothesized Structural Model

\begin{tabular}{|l|l|l|l|l|}
\hline Hypotheses & Coefficients & T-value & BC-CIs & Supported \\
\hline H1: SKH $\rightarrow$ OCB-S & & & & Yes \\
$\quad$ Total effect & $-0.225^{* * *}$ & 4.188 & $-0.374 \&-0.138$ & \\
Direct effect & $-0.162^{*}$ & 2.313 & $-0.295 \&-0.017$ & \\
\hline H2: SKH $\rightarrow$ Distrust & $0.512^{* * *}$ & 11.025 & $0.418 \& 0.595$ & Yes \\
\hline H3: Distrust $\rightarrow$ OCB-S & $-0.181^{* *}$ & 2.921 & $-0.297 \&-0.046$ & Yes \\
\hline H4: SKH $\rightarrow$ Distrust $\rightarrow$ OCB-S & $-0.093^{* *}$ & 2.743 & $-0.161 \&-0.025$ & Yes \\
\hline
\end{tabular}

$\mathrm{N}=317 ; *=<.05 ; * *=<.01 ; * * *=<.001 ;$ BC-CIs $=$ Bias-Corrected Confidence Intervals. 
TABLE 4

Measurement Invariance of the Hypothesized Model (5000 Permutations)

\begin{tabular}{|c|c|c|c|c|c|c|c|c|c|}
\hline \multirow[t]{2}{*}{ Constructs } & \multirow[t]{2}{*}{ Step 1} & \multirow{2}{*}{$\begin{array}{c}\text { Step 2 } \\
\mathrm{c}\end{array}$} & \multirow{2}{*}{$\begin{array}{l}5 \% \text { quantile } \\
\text { of } c_{u}\end{array}$} & \multirow[t]{2}{*}{ Result 1} & \multicolumn{4}{|c|}{ Step 3} & \multirow[t]{2}{*}{ Result 2} \\
\hline & & & & & MD & CIs & VD & CIs & \\
\hline $\mathrm{EH}$ & Yes & 1.000 & 1.000 & Yes & -0.262 & $\begin{array}{r}-0.223 \\
0.223\end{array}$ & -0.331 & $\begin{array}{r}-0.393 \\
0.427\end{array}$ & No \\
\hline PD & Yes & 1.000 & 1.000 & Yes & -0.324 & $\begin{array}{r}-0.221 \\
0.228\end{array}$ & -0.341 & $\begin{array}{r}-0.379 \\
0.400\end{array}$ & No \\
\hline RH & Yes & 1.000 & 1.000 & Yes & 0.017 & $\begin{array}{c}-0.215 \\
0.223(n s) \\
\end{array}$ & 0.096 & $\begin{array}{r}-0.218 \\
0.231 \\
\end{array}$ & Yes \\
\hline Distrust & Yes & 1.000 & 0.999 & Yes & -0.293 & $\begin{array}{r}-0.231 \\
0.220\end{array}$ & 0.011 & $\begin{array}{r}-0.293 \\
0.305\end{array}$ & No \\
\hline OCB-S & Yes & 0.996 & 0.999 & Yes & -0.165 & $\begin{array}{r}-0.222 \\
0.225\end{array}$ & -0.039 & $\begin{array}{r}-0.309 \\
0.326 \\
\end{array}$ & Yes \\
\hline
\end{tabular}

$\mathrm{c}=$ Original composite score correlation; $\mathrm{c}_{\mathrm{u}}=$ Perm CIs = Confidence intervals; $\mathrm{MD}=$ Mean difference; $\mathrm{VD}=$ Variance difference; Step 1 = Configural invariance (Same algorithms for both groups); Step 2 = Compositional invariance $($ Correlation $=1)$; Result $1=$ Partial measurement invariance established; Result $2=$ Full measurement invariance established 
TABLE 5

MGA of the Hypothesized Model (Saudi versus Foreign)

\begin{tabular}{|c|c|c|c|c|c|c|c|}
\hline \multirow[t]{2}{*}{ Hypotheses } & \multicolumn{2}{|c|}{ Foreign (134) } & \multicolumn{2}{|c|}{ Saudi (184) } & \multirow[t]{2}{*}{ Diff } & \multirow[t]{2}{*}{ H-p } & \multirow[t]{2}{*}{ Supported } \\
\hline & Coefficients & $\begin{array}{l}\text { BC- } \\
\text { CIs }\end{array}$ & Coefficients & $\begin{array}{l}\text { BC- } \\
\text { CIs }\end{array}$ & & & \\
\hline $\begin{array}{c}\text { H1: } \mathrm{SKH} \rightarrow \text { OCB-S } \\
\text { Total effect }\end{array}$ & $-0.214 *$ & -0.358 & $-0.320 * * *$ & -0.470 & 0.105 & 0.816 & No \\
\hline & & $\begin{array}{c}-0.011 \\
-0.306 \\
0.172\end{array}$ & $-0.229 * *$ & $\begin{array}{l}-0.142 \\
-0.392 \\
-0.043\end{array}$ & 0.130 & 0.808 & No \\
\hline $\mathrm{H} 2: \mathrm{SKH} \rightarrow$ Distrust & $0.598 * * *$ & $\begin{array}{l}0.466 \\
0.700\end{array}$ & $0.432 * * *$ & $\begin{array}{l}0.279 \\
0.558\end{array}$ & 0.167 & 0.967 & Yes \\
\hline H3: Distrust $\rightarrow$ OCB-S & $-0.193(\mathrm{~ns})$ & $\begin{array}{r}-0.362 \\
0.041\end{array}$ & $-0.210 * *$ & $\begin{array}{l}-0.363 \\
-0.044\end{array}$ & 0.017 & 0.549 & No \\
\hline $\mathrm{H} 4: \mathrm{SKH} \rightarrow$ Distrust $\rightarrow \mathrm{OCB}-\mathrm{S}$ & $-0.115(\mathrm{~ns})$ & $\begin{array}{r}-0.232 \\
0.022\end{array}$ & $-0.091 *$ & $\begin{array}{l}-0.180 \\
-0.021\end{array}$ & 0.025 & 0.366 & No \\
\hline
\end{tabular}

H- $p$ = Hensler's MGA p value; BC-CIs = Bias-Corrected Confidence Intervals; Diff = Difference; $\mathrm{ns}=$ Nonsignificant. 